\title{
Mental Contrasting With Implementation Intentions Reduces Drinking When Drinking Is Hazardous: An Online Self- Regulation Intervention
}

Health Education \& Behavior 2019, Vol. 46(4) 666-676 (C) 2019 Society for Public Health Education Article reuse guidelines: sagepub.com/journals-permissions DOI: I0.1I77/I090198119826284 journals.sagepub.com/home/heb (SSAGE

\author{
Sandra Wittleder, $\mathbf{P h D}^{1,2} \mathbb{D}$, Andreas Kappes, $\mathbf{P h D}^{3}$, Gabriele Oettingen, $\mathbf{P h D}^{1,2}$, \\ Peter M. Gollwitzer, $\mathrm{PhD}^{2,4}$, Melanie Jay, MD, MA', and Jon Morgenstern, $\mathbf{P h D}^{5}$
}

\begin{abstract}
Introduction. Drinking alcohol has detrimental health consequences, and effective interventions to reduce hazardous drinking are needed. The self-regulation intervention of Mental Contrasting with Implementation Intentions (MCII) promotes behavior change across a variety of health behaviors. In this study, we tested if online delivery of MCIl reduced hazardous drinking in people who were worried about their drinking. Method. Participants $(N=200$, female $=107)$ were recruited online. They were randomized to learn $\mathrm{MCll}$ or solve simple math problems (control). Results. Immediately after the intervention, participants in the MCll condition (vs. control) reported an increased commitment to reduce drinking. After I month, they reported having taken action measured by the Readiness to Change drinking scale. When drinking was hazardous (Alcohol Use Disorders Identification Test $\geq 8, n=85$ ), participants in the MCll condition indicated a decreased number of drinking days, $\exp (\beta)=0.47, \mathrm{Cl}$ (confidence interval) [-1.322, -.207], $p=.02$, and drinks per week, $\exp (\beta)=0.57, \mathrm{Cl}[0.94,5.5 \mathrm{I} 4]$, $p=.007$, compared with the control condition. Discussion. These findings demonstrate that a brief, self-guided online intervention ( $M d n=28$ minutes) can reduce drinking in people who worry about their drinking. Our findings show a higher impact in people at risk for hazardous drinking. Conclusion. MCll is scalable as an online intervention. Future studies should test the cost-effectiveness of the intervention in real-world settings.
\end{abstract}

\section{Keywords}

alcohol, computer-mediated health promotion, Mental Contrasting with Implementation Intentions (MCII), self-guided brief intervention, self-regulation

Excessive alcohol use is the third leading preventable cause of death in the United States (Stahre, Roeber, Kanny, Brewer, \& Zhang, 2014) and has detrimental health consequences (National Institute on Alcohol Abuse and Alcoholism, 2000) that cost the United States billions of dollars each year (Sacks, Gonzales, Bouchery, Tomedi, \& Brewer, 2010). Therefore, effective interventions to reduce hazardous drinking $^{1}$ are needed (World Health Organization, 2014); online interventions could save costs while increasing dissemination. Although they show promise as alternative treatments (Elliot, Carey, \& Bolles, 2008; Riper et al., 2014; Rooke, Thorsteinsson, Karpin, Copeland, \& Allsop, 2010), the evidence for the success of online interventions is still mixed (Bewick et al., 2008). The best framework for delivering online alcohol reduction interventions remains unknown (Balhara \& Verma, 2014). Mental Contrasting with Implementation Intentions (MCII; Oettingen, 2012, 2014; Oettingen \& Gollwitzer, 2010) entails two complementary self-regulation strategies: Mental Contrasting (MC) and
Implementation Intentions (II). Successful behavior change involves committing to goals, actively striving to reach them, and planning how to overcome potential obstacles to attaining those goals. MCII targets all of these tasks and thus promotes greater behavior change compared with the use of either strategy alone (Adriaanse et al., 2010; Kirk, Oettingen, $\&$ Gollwitzer, 2011), and it is an auspicious strategy to reduce drinking.

\footnotetext{
'University of Hamburg, Hamburg, Germany

${ }^{2}$ New York University, New York, NY, USA

${ }^{3}$ University of Oxford, Oxford, England

${ }^{4}$ University of Konstanz, Konstanz, Germany

${ }^{5}$ Northwell Health, New York, NY, USA

\section{Corresponding Author:}

Sandra Wittleder, Department of Medicine, New York University School of Medicine, 423 East 23rd Street, New York, NY 10010, USA.

Email: sandra.wittleder@nyulangone.org
} 
Mental contrasting comprises three steps. People first name a desired and feasible future wish (e.g., becoming the person I was before I started drinking). Second, they identify the best outcome of fulfilling this wish and vividly imagine this best outcome (e.g., not being dependent, feeling energetic, and accomplishing more tasks each day). Third, they identify a critical obstacle in themselves that stands in the way of realizing their wish and experiencing the best outcome; and then they vividly imagine this inner obstacle (e.g., feeling pressured to drink by friends). Mental Contrasting helps people understand how to overcome their obstacle (e.g., saying no when feeling pressured to drink) and energizes people to commit to and actively strive for their desired future (Oettingen, 2000, 2012). Even though mental contrasting on its own promotes successful goal pursuit and behavior change, people may struggle - particularly if the obstacle is challenging, as is often the case when people try to change a bad habit (Adriaanse, Gollwitzer, De Ridder, de Wit, \& Kroese, 2011; Webb \& Sheeran, 2006).

Implementation intentions are if-then plans that help people specify a goal-directed behavior in response to a critical situation (e.g., a good opportunity, a temptation, or a particular challenge or threat). In the framework of MCII, implementation intentions are geared toward overcoming difficult obstacles by forming an "if . . . (obstacle), then I will . . . (behavior or thought to overcome obstacle)" plan. For example, people might say to themselves: "If I feel pressured by my friends to order another drink, then I will tell them: Not today, maybe tomorrow!" (Gollwitzer, 1990, 1993, 1999, 2014). Implementation intentions unfold their effects when goal commitment is high, the situation specified in the "if" part is critical for behavior change, and the behavior specified in the "then" part is instrumental to behavior change (Sheeran, Webb, \& Gollwitzer, 2005). Mental Contrasting establishes all three prerequisites. It heightens goal commitment (Oettingen, 2012) and helps identify inner obstacles that can be specified as the situational cue for the "if" part (Kappes, Wendt, Reinelt, \& Oettingen, 2013). Mental Contrasting also helps find a means to overcome these obstacles, which can consequently be specified in the "then" part (Kappes, Singmann, \& Oettingen, 2012).

We and others have elucidated the mechanisms of MCII through experimental research. For instance, we discovered that changes in implicit cognition are critical mediators for the effects of mental contrasting as well as implementation intentions. After mental contrasting of feasible wishes, people interpret the current reality as a clear obstacle to behavior change (Kappes et al., 2013). Mental contrasting also strengthens the implicit cognitive associations between the desired future and the obstacle of current reality (Kappes \& Oettingen, 2014), as well as between these obstacles and instrumental means to overcome them (Kappes et al., 2012). These cognitive processes, outside of people's awareness, conjointly mediate changes in energization (Kappes \& Oettingen, 2014; Oettingen et al., 2009), in commitment and performance (Kappes et al., 2012), as well as in the readiness to plan how to overcome the obstacles of the current reality (Kappes et al., 2013; Oettingen, Pak, \& Schnetter, 2001).

Implementation Intentions increase the accessibility of the situational cue specified in the "if" part (Achtziger, Bayer, \& Gollwitzer, 2012; Parks-Stamm, Gollwitzer, \& Oettingen, 2007; Webb \& Sheeran, 2007). Once this critical situation is encountered, they foster the automatic initiation of the goal-directed response specified in the "then" part (i.e., the specified response is executed fast, efficiently, and no conscious intent is needed; Bayer, Achtziger, Gollwitzer, \& Moskowitz, 2009; Brandstätter, Lengfelder, \& Gollwitzer, 2001; Gollwitzer \& Brandstätter, 1997; Miles \& Proctor, 2008; Webb \& Sheeran, 2007, 2008).

Past studies have demonstrated that MCII has promoted healthy behaviors such as regular exercise continued for over 4 months and following a healthy diet for up to 2 years (Stadler, Oettingen, \& Gollwitzer, 2009, 2010). It has also promoted vigorous exercise and weight loss in stroke patients for over 1 year (Marquardt, Oettingen, Gollwitzer, Sheeran, \& Liepert, 2017). Notably, MCII was particularly effective when behavior change was challenging rather than easy (Gollwitzer, 2014; Oettingen, 2012; Oettingen, Kappes, Guttenberg, \& Gollwitzer, 2015). For example, MCII enhanced self-regulation for schoolchildren at risk for ADHD (attention-deficit/ hyperactivity disorder), thereby demonstrating its value for those who might need it the most (Gawrilow, Morgenroth, Schultz, Oettingen, \& Gollwitzer, 2013).

For people who need help with an alcohol disorder or for those who are at risk, to date the U.S. Community Preventive Service Task Force (2013) recommends the use of Screening, Brief Intervention, and Referral to Treatment (SBIRT). Commonly, SBIRT is delivered by a trained health care provider or other interventionist. There is evidence, however, that the SBIRT approach can also be extended to electronic screening and brief intervention (U.S. Preventive Services Task Force, 2013).

One of the components of SBIRT is motivational interviewing (MI; Miller \& Rollnick, 1991). In MI, an interventionist utilizes a set of communication strategies (e.g., affirmations or reflective listening) to help people overcome their ambivalence and increase their motivation to change. Another intervention using $\mathrm{MI}$ is the national alcohol helpline in Sweden (Ahacic, Nederfeldt, \& Helgason, 2014). It is a telephone-based intervention delivered by counselors who have received comprehensive training in MI and basic training in the use of elementary cognitive behavior therapy (CBT) tools (e.g., positive reinforcement or gradual exposure; Beck, 2011).

One common characteristic of MI, CBT, and MCII is that they are highly individualized, and people can create their own specific goals. One main difference with regard to $\mathrm{MCII}$ is that $\mathrm{MI}$ and $\mathrm{CBT}$ require conversation between two people- the patient/client and the interventionist. In contrast, MCII does not require any trained health professional 
or interventionist. Furthermore, while MI and CBT approaches aim, for example, at eliciting change talk or increasing self-efficacy beliefs, MCII directly initiates behavior change through nonconscious cognitive mechanisms (e.g., a person forms strong automatic associations between their desired outcome and their personal obstacle). MCII entails a set order of four steps, which involve distinct goal-related concepts (i.e., wish, outcome, obstacle, and plan). It assists people to identify a wish or desired future, identify and imagine the best outcome, identify and imagine the main inner obstacle, and finally formulate and imagine an if-then plan of how to overcome the obstacle. Patients can be taught to autonomously go through these four steps on their own. This autonomy makes the procedure of MCII potentially highly scalable and accessible to the general population.

The present research explored the feasibility of online delivery of MCII and addressed the need for additional evidence to determine the best framework for alcohol consumption-related online interventions. We predicted that MCII would increase commitment to reduce one's drinking and it would increase readiness to take action, as measured by the Readiness to Change (RTC) drinking scale, relative to a control condition. We also predicted that MCII would reduce drinking at a followup assessment. MCII should particularly help when behavior change was difficult (i.e., for people who reported hazardous drinking at baseline), relative to control participants. Finally, we also explored whether commitment to reduce drinking and taking action on the RTC mediate MCII effects.

\section{Method}

\section{Participants}

We conducted a randomized controlled trial of online delivery of MCII versus control in participants recruited online from the general community. Participants responded to the advertisement "Are you worried about your drinking? Is alcohol a problem for you?" posted via Amazon's MTurk website, a crowdsourcing Internet marketplace that researchers have utilized to recruit participants for online experiments (Buhrmester, Kwang, \& Gosling, 2011). Participants had to be at least 18 years old, which is required in order to get access to Amazon's MTurk website. There was no additional screening. The institutional review board of a large American university approved this study. Participants were asked to complete assessments at two time points: baseline and 1 month later. In Part 1, we assessed baseline drinking behavior, delivered the MCII intervention or control, and assessed the dependent variables (e.g., motivation) as well as demographic information. Completing the first part required about half an hour ( $M d n=28$ minutes). Participants' MTurk worker IDs were collected for follow-up invitations and to link responses across time. We stored MTurk worker IDs separately to ensure anonymity. After 1 month, we reassessed dependent variables (e.g., motivation and drinking outcomes). Compensation was $\$ 3$ for completing both portions of the study. Delivery of MCII versus control and all data assessments were completed online using the Qualtrics online survey software. Participants were evenly randomized to one of the two groups using the survey flow randomization of the Qualtrics software. Participants were blind to condition throughout the study.

\section{Intervention}

MCII Condition. The intervention was self-guided, and instructions were delivered online (instructions delivered to participants online; see Supplemental Appendix A, available in the online version of this article). For all steps, participants typed their answers into the online survey. To familiarize themselves with MCII, participants started by identifying an important wish that pertained to any life domain and could be achieved in the next 4 weeks (e.g., finishing an application). Participants then identified the best outcome associated with realizing their wish (e.g., feeling free and satisfied). They were instructed to imagine this best outcome and write down all of their related thoughts. Thereafter, participants identified the most important inner obstacle that prevents them from realizing their wish (e.g., getting distracted at night). They imagined this obstacle and wrote down all of the associated thoughts. Next, participants identified an action to overcome the inner obstacle and formed an implementation intention according to the following format: "If (here you name your obstacle), then I will (here you name your action)." Finally, participants reviewed the steps of MCII: (a) formulate a wish, (b) identify and imagine the best outcome, (c) identify and imagine the most important inner obstacle, and (d) formulate an if-then plan. They learned that people could use this strategy to realize their wishes (see Figure 1). Participants then applied the MCII exercise to reducing or stopping their drinking. To demonstrate everyday applicability, participants finally performed an MCII exercise for a wish they wanted to realize within the next 24 hours (Oettingen, 2014; Stadler et al., 2009, 2010 ), one that could pertain to alcohol or any other wish or goal.

Control Condition. Participants in the control condition read a cover story stating that realizing wishes is related to the ability to focus attention. To help train this ability, they solved 19 arithmetic problems modified from the "Concentration Achievement Test" (Düker \& Lienert, 1965). For each of these problems, participants first solved two mathematical equations (e.g., $7-3$ and $4+5$ ), remembered the results, subtracted the lower number from the higher number, and entered the answer. This light placebo intervention required intense concentration and therefore prevented participants from spontaneously using self-regulation strategies. 


\section{Condition}

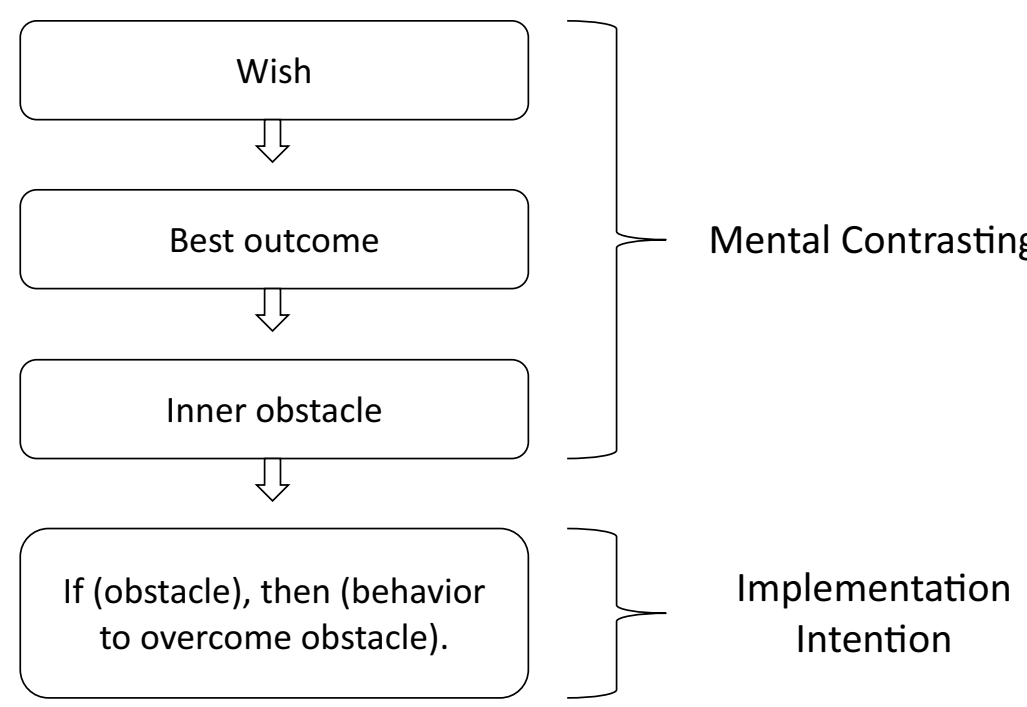

Figure I. Overview of the steps in MCII. MCII = Mental Contrasting with Implementation Intentions.

\section{Measures}

Commitment to Reduce Drinking. Participants indicated their commitment to reduce or stop drinking immediately after the intervention at baseline ( 8 items; $\alpha=.98$; e.g., "How committed are you to reduce or stop drinking?") on a scale from 1 (Not at all) to 7 (Very) (Oettingen et al., 2009).

Readiness to Change Drinking. Participants completed the RTC (Rollnick, Heather, Gold, \& Hall, 1992) twice. The first time was immediately after the intervention at baseline, and the second time was at the 1-month follow-up. RTC comprises three stages: precontemplation, contemplation, and action (the most advanced stage). Answers were combined for each of the three stages (four items each) at both time points ( $\alpha \mathrm{s}=.78$ to .89$)$.

Drinking Outcomes. At baseline and the 1-month follow-up, we administered the Alcohol Timeline Follow-Back Method (Sobell $\&$ Sobell, 1992), referencing the past 14 days. The Timeline Follow-Back Method shows psychometrically sound properties when administered online (Pedersen, Grow, Duncan, Neighbors, \& Larimer, 2012). Participants retrospectively reported their drinking events and the number of standard drinks consumed for each day. The number of drinking days per week served as a measure of frequency and the number of drinks per week as a measure of quantity. ${ }^{2}$ To assess drinking-related problems, participants completed the Alcohol Problems Questionnaire (APQ; Williams \& Drummond, 1994) at both the baseline $(\alpha=.88)$ and the 1-month follow-up $(\alpha=.80)$, again referencing the past 14 days.

Perceived Change. At the end of the 1-month follow-up, participants indicated how much their alcohol consumption had changed (i.e., To what extent do you feel that your alcohol consumption changed over the past 4 weeks?) and how much their everyday life had changed (i.e., To what extent do you feel that your everyday life changed over the past 4 weeks?) on a scale from 1 (Not at all) to 7 (Very).

Moderator Variable: Hazardous Drinking. Before the intervention, participants completed the Alcohol Use Disorders Identification Test (AUDIT; Babor, Higgins-Biddle, Saunders, \& Monteiro, 2001). Scores of 8 and higher indicated hazardous alcohol use $(\alpha=.88){ }^{3}$

\section{Data Analytic Plan}

Analyses were performed using SPSS. A $p$ value $<.05$ was regarded as statistically significant, two-tailed. To explore differences between completers and noncompleters and baseline differences between intervention and control participants, we performed a series of univariate analysis of variances (ANOVAs) and $\chi^{2}$ tests. To examine differences in commitment, readiness to change, and perceived change between conditions, we performed univariate ANOVAs. To test whether MCII reduces drinking, particularly for people experiencing hazardous drinking, 


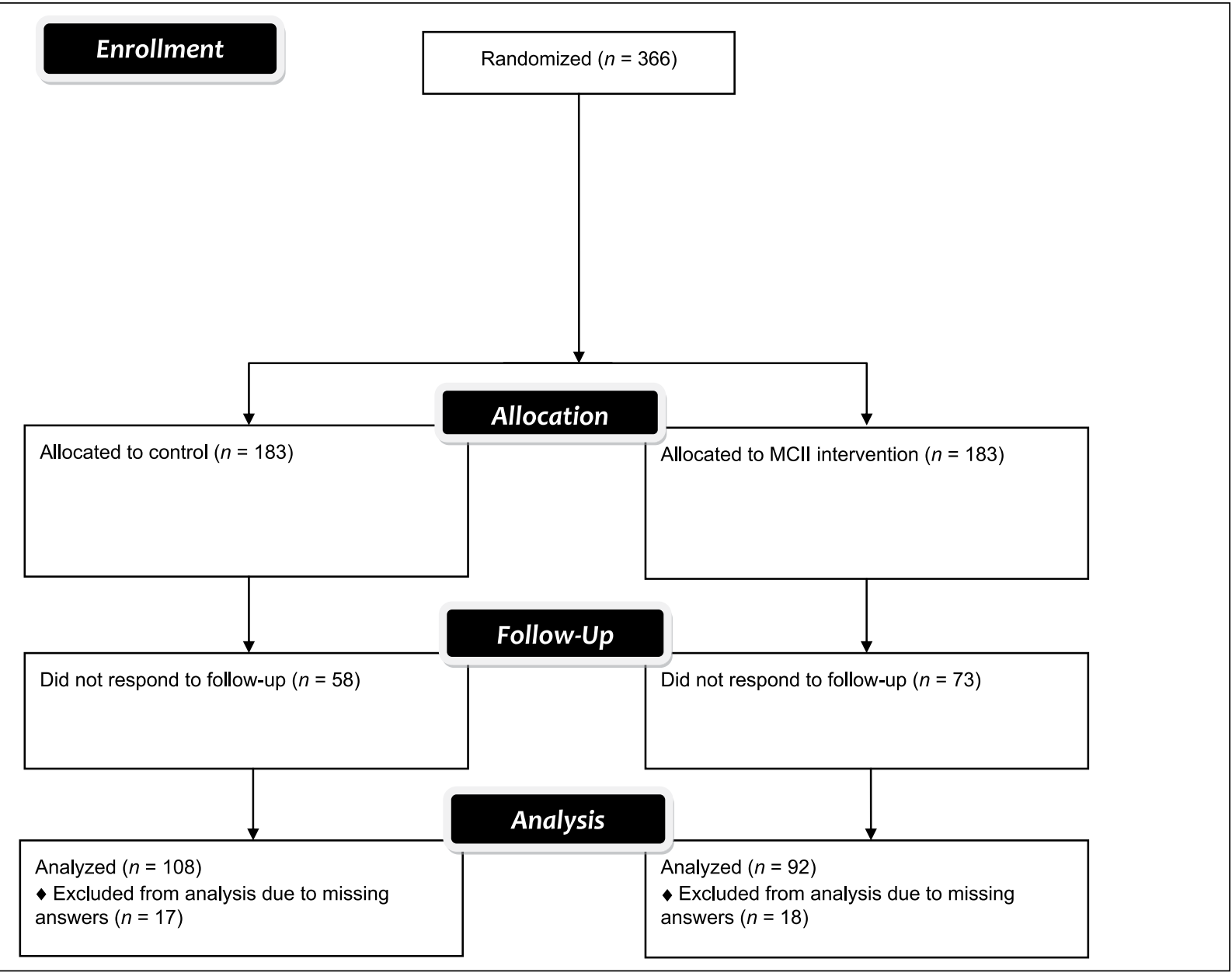

Figure 2. Participant flow. MCll = Mental Contrasting with Implementation Intentions.

we used the Generalized Estimating Equation (GEE) approach (Liang \& Zeger, 1986). The GEE approach can be used to model nonnormally distributed variables (e.g., count variables). The drinking indicators were drinking days, drinks per week, and alcohol-related problems. These variables were not normally distributed and displayed overdispersion. Therefore, we used negative binominal GEE models. We recoded AUDIT scores into a dichotomous variable, with 1 coding nonhazardous drinking (AUDIT $<8$ ) and 0 coding hazardous drinking (AUDIT $\geq 8$ ). The MCII condition was coded as 0 , and the control condition was coded as 1 . A series of $2 \times 2$ negative binominal GEE models with Condition (MCII vs. control), and AUDIT (nonhazardous vs. hazardous) were used to compare MCII effects for nonhazardous and hazardous drinkers. Baseline levels of each drinking indicator were covariates. Before analyses, we corrected outliers by changing values greater than or equal to 3.29 standard deviations above the mean to be one unit greater than the greatest nonoutlier value (Tabachnick \& Fidell, 2012). To test our mediation hypothesis, we computed a composite score of frequency and quantity of alcohol consumption and performed serial multiple mediator analyses using ordinary least squares path analysis (Model 6 in the PROCESS macro; Hayes, 2013).

\section{Results}

\section{Sample}

A total of 366 participants were randomly assigned to the MCII condition $(n=183)$ or the control condition $(n=183)$. Out of these participants, 131 participants $(35.79 \%)$ did not respond to 1-month follow-up invitations, and 35 participants $(10.02 \%)$ had incomplete data. ${ }^{4}$ For detailed participant flow, see Figure 2. Attrition was not significantly different across conditions, $\chi^{2}(1, N=131)=$ $1.72, p=.19$. Completers versus noncompleters did not significantly differ in gender, $\chi^{2}(1, N=328)=3.18, p=.08$, AUDIT, APQ baseline, age, income, or education, $F \mathrm{~s}_{\text {univariate }}(1,252)=.002$ to $3.20, p \mathrm{~s}>.07, \eta_{p}^{2} \mathrm{~s}<.02$. 
Table I. Demographics of Participants.

\begin{tabular}{|c|c|c|}
\hline Demographics & Control $(n=108), n(\%)$ & MCII $(n=92), n(\%)$ \\
\hline \multicolumn{3}{|l|}{ Gender } \\
\hline Female & $56(52 \%)$ & 51 (55\%) \\
\hline Male & $52(48 \%)$ & $4 I(45 \%)$ \\
\hline \multicolumn{3}{|l|}{ Annual household income $(\$)$} \\
\hline No income & $6(6 \%)$ & $2(2 \%)$ \\
\hline$<5,000$ & $4(4 \%)$ & $9(10 \%)$ \\
\hline $5,000-11,999$ & $9(8 \%)$ & $3(3 \%)$ \\
\hline $12,000-19,999$ & $4(4 \%)$ & $7(8 \%)$ \\
\hline $20,000-39,999$ & $33(31 \%)$ & 31 (34\%) \\
\hline $40,000-59,999$ & $14(13 \%)$ & $18(20 \%)$ \\
\hline $60,000-79,999$ & $9(8 \%)$ & $10(11 \%)$ \\
\hline$>80,000$ & $24(22 \%)$ & $10(11 \%)$ \\
\hline \multicolumn{3}{|l|}{ Education } \\
\hline Less than high school & $2(2 \%)$ & I (I\%) \\
\hline High school diploma or GED & $10(11 \%)$ & $9(10 \%)$ \\
\hline Some college & $36(33 \%)$ & 31 (34\%) \\
\hline College degree & $32(30 \%)$ & $20(22 \%)$ \\
\hline Associates degree & $2(2 \%)$ & $12(13 \%)$ \\
\hline Some graduate or professional training & $5(5 \%)$ & $6(7 \%)$ \\
\hline Graduate or professional degree & $17(16 \%)$ & $12(13 \%)$ \\
\hline \multicolumn{3}{|l|}{ Employment status } \\
\hline Disabled & - & $2(2 \%)$ \\
\hline Homemaker & $16(15 \%)$ & $2(2 \%)$ \\
\hline Retired & - & $2(2 \%)$ \\
\hline Self-employed & $3(3 \%)$ & II (I2\%) \\
\hline Student & II (10\%) & II (I2\%) \\
\hline Unemployed not seeking work & $13(12 \%)$ & $2(2 \%)$ \\
\hline Unemployed seeking work & $7(6 \%)$ & $9(10 \%)$ \\
\hline Working part time & $10(11 \%)$ & $5(5 \%)$ \\
\hline Working full-time $>35$ hours/week & $44(41 \%)$ & $47(51 \%)$ \\
\hline \multicolumn{3}{|l|}{ Race } \\
\hline African American, Black, of African descent & $4(4 \%)$ & $5(5 \%)$ \\
\hline American Indian (Native American) & $\mathrm{I}(\mathrm{l} \%)$ & $\mathrm{I}(1 \%)$ \\
\hline Asian/Pacific Islander & $6(6 \%)$ & $5(5 \%)$ \\
\hline Hispanic/Latino & $3(3 \%)$ & $6(7 \%)$ \\
\hline White, Caucasian, European descent & $94(87 \%)$ & $80(87 \%)$ \\
\hline Other/unknown & - & - \\
\hline \multicolumn{3}{|l|}{ Hazardous drinking } \\
\hline AUDIT $<8$ & 67 (62\%) & 48 (52\%) \\
\hline AUDIT $\geq 8$ & $41(38 \%)$ & 44 (48\%) \\
\hline
\end{tabular}

Note. Multiple answers were possible for race. $\mathrm{MCll}=$ Mental Contrasting with Implementation Intentions; AUDIT = Alcohol Use Disorders Identification Test.

The final sample of $N=200(\mathrm{MCII}=92 ;$ control $=108)$ consisted of 107 females (53.5\%). Age varied between 20 and 67 years $(M=35.0, S D=12.0)$. The sample was $87.0 \%$ Caucasian. Table 1 presents participants' demographics. Drinking was hazardous for 85 participants $(42.5 \%)$ using the cutoff point of 8 on the AUDIT ( $M=8.15, S D=6.93$; Babor et al., 2001). Participants experienced an average of 4 out of 23 alcohol-related problems within the past 2 weeks (APQ: $M=3.83, S D=4.09)$. Table 2 shows means, standard deviations, and correlations for baseline measures. Conditions did not significantly differ in gender, $\chi^{2}(1, N=200)=.26$, $p=.61$, AUDIT, APQ baseline, age, income, or education, $F \mathrm{~s}_{\text {univariate }}(1,184)=.02$ to $1.39, p \mathrm{~s}>.23, \eta_{p}^{2} \mathrm{~s}<.009$.

\section{Commitment}

MCII increased commitment to reduce drinking. Results of a univariate ANOVA showed that participants in the 
Table 2. Means, Standard Deviations, and Correlations for Baseline Measures.

\begin{tabular}{|c|c|c|c|c|c|c|c|c|}
\hline Measure & $M(S D)$ & I & 2 & 3 & 4 & 5 & 6 & 7 \\
\hline I. AUDIT & $8.17(6.94)$ & - & & & & & & \\
\hline 2. APQ & $3.87(4.26)$ & $.69 * *$ & - & & & & & \\
\hline 3. Drinking days per week & $2.81(2.02)$ & $.41 * *$ & $.27^{* *}$ & - & & & & \\
\hline 4. Drinks per week & $3.54(3.19)$ & $.67^{*}$ & $.48^{* *}$ & $.74 * *$ & - & & & \\
\hline 5. Age & $35.08(12.0)$ & $-.15 *$ & -.13 & .01 & -.09 & - & & \\
\hline 6. Income & $5.35(1.90)$ & $-.16 *$ & $-.15^{*}$ & .01 & -.09 & .13 & - & \\
\hline 7. Education & $5.04(1.62)$ & -.08 & -.08 & .10 & .01 & .02 & $.31 *$ & 一 \\
\hline
\end{tabular}

Note. AUDIT $=$ Alcohol Use Disorder Identification Test; APQ = Alcohol Problems Questionnaire. $*_{p}<.05 . *_{p}<.001$.

MCII condition reported stronger commitment to reduce or stop drinking $(M=3.70, S D=1.94)$ than the control condition $(M=2.99, S D=2.06), F(1,198)=6.35$, $p=.02, \eta_{p}^{2}=.03$.

\section{Readiness to Change}

After 4 weeks, participants reported to have taken more action toward changing their drinking in the MCII $(M=0.11, S D=1.08)$ than in the control group $(M=-0.27$, $S D=1.02)$. Condition had a significant effect on the action score (e.g., "I am actually changing my drinking habits right now"), $F(1,198)=6.42, p=.01, \eta_{p}{ }^{2}=.03$. There was no significant effect of Condition on the precontemplation or the contemplation score, $F \mathrm{~s}_{\text {univariate }}(1,198)=.62$ to 3.37 , $p \mathrm{~s}>.06, \eta_{p}^{2} \mathrm{~s}<.02$. Similarly, there was also no significant effect of Condition on the RTC stages (i.e., precontemplation, contemplation, and action) when RTC was measured directly after the manipulation, $F \mathrm{~s}_{\text {univariate }}(1,193)=1.02$ to $1.51, p \mathrm{~s}>.21, \eta_{p}{ }^{2} \mathrm{~s}<.009$.

\section{Drinking Behavior}

Based on past research demonstrating that MCII is particularly effective when behavior change is challenging (Gollwitzer, 2014; Oettingen, 2012), we expected that MCII would have the strongest effects when drinking was hazardous. In line with this hypothesis, we observed the predicted interaction effects of Condition by AUDIT on drinking days per week (frequency), $\exp (\beta)=0.57,95 \%$ confidence interval (CI) $[0.94,5.514], p<.001$, and drinks per week (quantity), $\exp (\beta)=0.47,95 \%$ CI $[-1.322,-.207], p=.007 .{ }^{5}$ For the group of participants who reported hazardous drinking at baseline (i.e., AUDIT $\geq 8$ ), participants in the MCII condition were $43 \%$ less likely to report drinking days at 1-month follow-up than the control condition, and 53\% less likely to report drinks consumed at follow-up than the control condition. Moreover, when drinking was hazardous, participants in the MCII condition decreased their alcohol consumption from baseline to follow-up by $37 \%(M=1.21)$ for drinking days, and by $55 \%(M=9.98)$ for drinks per week. Figure 3 depicts mean changes in drinking days and drinks per week by Condition and AUDIT.

In contrast, for drinking-related problems, GEE analyses revealed no significant interaction effect, $p=.48$, of Condition and AUDIT. Table 3 contains means and standard deviations at baseline and 1-month follow-up by Condition and AUDIT for drinking days, drinks per week, and drinking-related problems.

\section{Affects Drinking Reduction via Commitment and Readiness to Change}

Serial multiple mediation analyses adjusting for baseline drinking revealed that condition indirectly influenced follow-up drinking (indirect $=-.023 ; 95 \%$ CI $[-.055,-.001]$ ) through its effect on commitment and action score (RTC). Participants in the MCII condition (vs. the control condition) heightened commitment to reduce or stop drinking, which in turn predicted increased reported action on the RTC scale, which finally predicted reduced drinking at follow-up.

\section{Perceived Change}

MCII increased perceived change in alcohol consumption. Results of a univariate ANOVA showed that participants in the MCII condition perceived more change $(M=3.41, S D=$ 2.16) than the control condition $(M=2.50, S D=1.90), F(1$, $198)=10.11, p=.002, \eta_{p}^{2}=.05$. MCII also helped change their everyday life. Results of a univariate ANOVA showed 


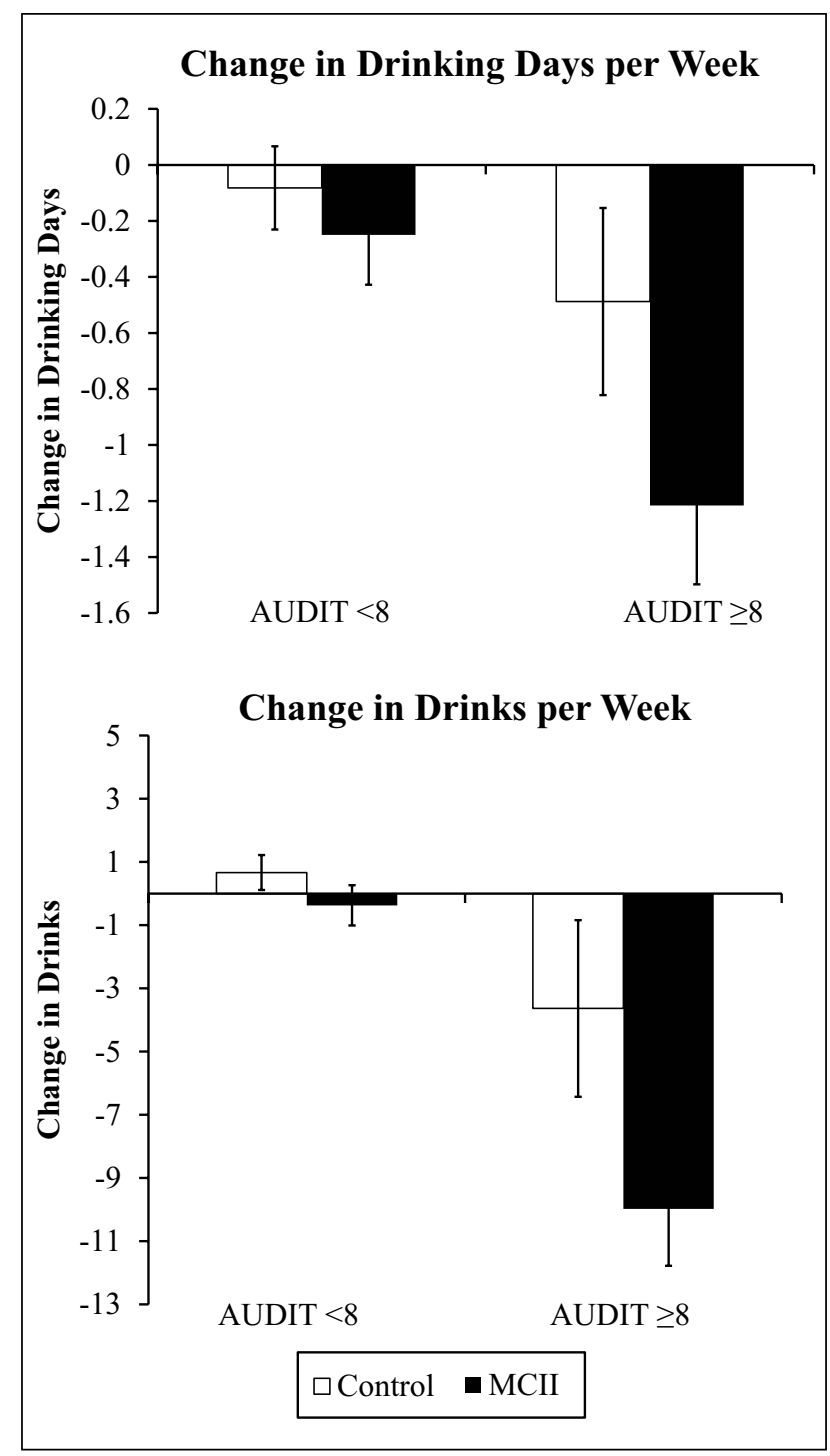

Figure 3. Mean change for drinking days per week, drinks per week by condition (MCll vs. Control), and hazardous drinking (i.e., AUDIT). MCll = Mental Contrasting with Implementation Intentions; AUDIT = Alcohol Use Disorders Identification Test.

that participants in the MCII condition reported higher perceived change in life $(M=3.10, S D=2.13)$ than the control condition $(M=2.52, S D=1.98), F(1,198)=3.92, p<.05$, $\eta_{p}^{2}=.02$

\section{Discussion}

We examined MCII as a brief online intervention to help people recruited online who wished to reduce their drinking. In line with previous research on MCII benefitting various indicators of health behavior (Oettingen \& Gollwitzer, 2018), our participants benefitted from MCII more compared with the control condition. We found that MCII immediately boosted commitment to reduce drinking and 1 month later fostered taking action to change drinking. Our finding that MCII only affected the action score of the Readiness to Change Scale, rather than the precontemplation and contemplation scores, suggests that (a) we were successful in recruiting participants who indeed wanted to reduce or stop their drinking and (b) participants in the MCII condition took action to reduce their drinking over the course of that month. Importantly, participants whose drinking was hazardous (i.e., AUDIT $\geq 8$ ) and who were in the MCII condition reported drinking less 1 month after the intervention than respective participants in the control condition.

There are several limitations to our study. First, even though we recruited people who worried about their drinking, we did not prescreen study participants for hazardous drinking. Still, more than $40 \%$ of the sample met the hazardous drinking threshold (i.e., AUDIT $\geq 8$ ). Moderation analyses indicated that MCII was especially valuable for these drinkers. Future research should determine whether the present results replicate in a sample of even more hazardous drinkers than the ones in the present sample. Second, we found that MCII did not reduce alcohol-related problems (i.e., APQ scale). This finding might have been due to a floor effect. As the present sample was not preselected for hazardous drinking, people reported a low number of alcohol-related problems at baseline $(M=3.87, S D=4.26)$. Third, our measures relied on participants' self-reported answers. Future studies should replicate the present findings utilizing more objective measures of alcohol consumption. Fourth, we only had a brief follow-up period of 1 month-thus efficacy of MCII on long-term drinking reduction still needs to be established. Finally, even though our dropout rate of $35.79 \%$ is common for studies on MTurk, it is high compared with retention observed in clinical trials. Moreover, although our analyses indicate that attrition was not dependent on condition, there is still a possibility that certain participants (e.g., more conscientious individuals) may have been more likely to respond to follow-up invitations than others (Zhou \& Fishbach, 2016).

Given the majority of our sample identified as Caucasian, future studies need to confirm the applicability to the general population. Furthermore, elaborating on wishes to reduce drinking in the MCII condition might have enhanced social desirability to report success. However, we advertised the control condition as an exercise to help reach personal goals; this should have spurred similar feelings of social desirability. Still, MCII produced its beneficial effects on drinking reduction as compared with the control group. Also, various studies found that enhanced social desirability could not explain MCII effects (Christiansen, Oettingen, Dahme, \& Klinger, 2010; Stadler et al., 2009, 2010).

Despite these limitations, benefits of MCII include its easy-to-learn structure and time-saving use. It can be selfadministered without the help of a coach or a therapist. These attributes are in contrast to other interventions such as MI (Miller \& Rollnick, 1991), CBT (Beck, 2011), or providing normative feedback (Walters \& Neighbors, 
Table 3. Means for Drinking Days per Week, Drinks per Week, and Drinking-Related Problems at Baseline and Follow-Up by Condition and Hazardous Drinking (i.e., AUDIT).

\begin{tabular}{|c|c|c|c|c|}
\hline \multirow[b]{2}{*}{ Hazardous drinking } & \multicolumn{2}{|c|}{ Control } & \multicolumn{2}{|c|}{$\mathrm{MCll}$} \\
\hline & Baseline, $M(S D)$ & Follow-up, $M(S D)$ & Baseline, $M(S D)$ & Follow-up, $M(S D)$ \\
\hline \multicolumn{5}{|c|}{ Drinking days per weeks } \\
\hline AUDIT $<8$ & $2.11(1.84)$ & $2.02(1.76)$ & $2.48(1.88)$ & $2.23(2.20)$ \\
\hline AUDIT $\geq 8$ & $3.79(1.97)$ & $3.31(1.99)$ & $3.28(2.05)$ & $2.07(1.89)$ \\
\hline \multicolumn{5}{|l|}{ Drinks per week } \\
\hline AUDIT $<8$ & $5.30(5.59)$ & $5.96(6.25)$ & $6.02(5.01)$ & $5.65(6.74)$ \\
\hline AUDIT $\geq 8$ & $21.39(16.43)$ & $17.76(15.09)$ & I7.8I (13.00) & $7.83(7.14)$ \\
\hline \multicolumn{5}{|c|}{ Drinking-related problems } \\
\hline AUDIT $<8$ & $1.96(2.46)$ & $1.91(2.13)$ & $2.13(2.13)$ & $1.96(2.05)$ \\
\hline AUDIT $\geq 8$ & $7.13(4.42)$ & $4.00(3.19)$ & $5.57(4.85)$ & $3.21(3.36)$ \\
\hline
\end{tabular}

Note. AUDIT $=$ Alcohol Use Disorder Identification Test; $\mathrm{MCll}=$ Mental Contrasting with Implementation Intentions.

2005), which require gathering individual behavior and comparing it with relevant norms. Furthermore, many hazardous drinkers shy away from seeking professional help and prefer online self-help outside of conventional settings (Cunningham \& Breslin, 2004; Cunningham \& van Mierlo, 2009; Koski-Janne \& Cunningham, 2001). MCII is auspicious, as it might reach drinkers who otherwise would not seek treatment.

In conclusion, a brief self-guided online MCII intervention ( $M d n=28$ minutes) reduced drinking in an online community sample of Amazon's MTurk website users for persons at risk for hazardous drinking. MCII, therefore, has promise to help those who want to reduce their hazardous drinking. Future studies should test the cost-effectiveness of the online intervention in real-world settings.

\section{Authors' Note}

Sandra Wittleder is now at NYU School of Medicine. Andreas Kappes is now at City, University of London.

\section{Author Contributions}

All authors developed the study hypotheses and contributed to the study design. S. Wittleder performed the data collection, analysis, and interpretation under the supervision of A. Kappes, G. Oettingen, and P. M. Gollwitzer. S. Wittleder, A. Kappes, and G. Oettingen drafted the manuscript, and P. M. Gollwitzer, M. Jay, and J. Morgenstern provided critical revisions. All authors approved the final version of the paper for submission.

\section{Declaration of Conflicting Interests}

The authors declared no potential conflicts of interest with respect to the research, authorship, and/or publication of this article.

\section{Funding}

The authors disclosed receipt of the following financial support for the research, authorship, and/or publication of this article: This research was funded in part by the German Research Foundation (U-4701-DFG-1601). P.M.G was supported in part by the German Research Foundation (DFG, for 2374).

\section{Notes}

1. In World Health Organization terminology, hazardous drinking confers the risk of physical and/or psychological harm (Edwards, Arif, \& Hodgson, 1981).

2. If participants had missing responses for more than 2 days, drinking indicators were not calculated.

3. Additional covariates were incentive, short- and long-term expectations, normative beliefs, and perceived control, with respect to reduced drinking (see Fishbein \& Ajzen, 2009). Completers versus noncompleters and conditions did not differ on these measures.

4. Inclusion versus exclusion of participants with incomplete data did not affect the significance levels of results.

5. The drinking indicators were correlated at $r=.74$, and thus, we included a Bonferroni adjustment $(p=.025)$.

\section{Supplemental Material}

Supplemental Appendix A is available in the online version of this article at https://journals.sagepub.com/home/heb.

\section{ORCID iD}

Sandra Wittleder iD https://orcid.org/0000-0003-2108-404X

\section{References}

Achtziger, A., Bayer, U. C., \& Gollwitzer, P. M. (2012). Committing to implementation intentions: Attention and memory effects for selected situational cues. Motivation and Emotion, 36, 287-303.

Adriaanse, M. A., Gollwitzer, P. M., De Ridder, D. T. D., de Wit, J. B. F., \& Kroese, F. M. (2011). Breaking habits with implementation intentions: A test of underlying processes. Personality and Social Psychology Bulletin, 37, 502-512.

Adriaanse, M. A., Oettingen, G., Gollwitzer, P. M., Hennes, E. P., De Ridder, D. T. D., \& De Wit, J. B. F. (2010). When planning is not enough: Fighting unhealthy snacking habits by Mental Contrasting with Implementation Intentions (MCII). European Journal of Social Psychology, 40, 1277-1293.

Ahacic, K., Nederfeldt, L., \& Helgason, A. R. (2014). The national alcohol helpline in Sweden: An evaluation of its first year. Substance Abuse Treatment, Prevention, and Policy, 9, 28. doi:10.1186/1747-597X-9-28 
Babor, T. F., Higgins-Biddle, J. C., Saunders, J. B., \& Monteiro, M. G. (2001). AUDIT: The Alcohol Use Disorders Identification Test: Guidelines for use in primary care. Geneva, Switzerland: World Health Organization, Department of Mental Health and Substance Dependence.

Balhara, Y., \& Verma, R. (2014). A review of web based interventions focusing on alcohol use. Annals of Medical and Health Sciences Research, 4, 472-480.

Bayer, U. C., Achtziger, A., Gollwitzer, P. M., \& Moskowitz, G. (2009). Responding to subliminal cues: Do if-then plans facilitate action preparation and initiation without conscious intent? Social Cognition, 27, 183-201.

Beck, J. S. (2011). Cognitive behavior therapy: Basics and beyond. New York, NY: Guilford Press.

Bewick, B. M., Trusler, K., Barkham, M., Hill, A. J., Cahill, J., \& Mulhern, B. (2008). The effectiveness of web-based interventions designed to decrease alcohol consumption: A systematic review. Preventive Medicine, 47, 17-26.

Brandstätter, V., Lengfelder, A., \& Gollwitzer, P. M. (2001). Implementation intentions and efficient action initiation. Journal of Personality and Social Psychology, 81, 946-960.

Buhrmester, M., Kwang, T., \& Gosling, S. (2011). Amazon's Mechanical Turk: A new source of inexpensive, yet highquality, data? Perspectives on Psychological Science, 6, 3-5.

Christiansen, S., Oettingen, G., Dahme, B., \& Klinger, R. (2010). A short goal-pursuit intervention to improve physical capacity: A randomized clinical trial in chronic back pain patients. Pain, 149, 444-452.

Cunningham, J. A., \& Breslin, F. C. (2004). Only one in three people with alcohol abuse or dependence ever seek treatment. Addictive Behaviors, 29, 221-223.

Cunningham, J. A., \& van Mierlo, T. (2009). Methodological issues of Internet-based interventions for problem drinking. Drug and Alcohol Review, 28, 12-17.

Düker, H., \& Lienert, G. A. (1965). Der Konzentrations-LeistungsTest $(K L T)$ [The Concentration Performance Test]. Göttingen, Germany: Verlag für Psychologie, Hogrefe.

Edwards, G., Arif, A., \& Hodgson, R. (1981). Nomenclature and classification of drug and alcohol-related problems: A WHO memorandum. Bulletin of the World Health Organization, 59, 225-242.

Elliot, J. C., Carey, K. B., \& Bolles, J. R. (2008). Computer-based interventions for college drinking: A qualitative review. Addictive Behaviors, 33, 994-1005.

Fishbein, M., \& Ajzen, I. (2009). Predicting and changing behavior: The reasoned action approach. New York, NY: Psychology Press.

Gawrilow, C., Morgenroth, K., Schultz, R., Oettingen, G., \& Gollwitzer, P. M. (2013). Mental contrasting with implementation intentions enhances self-regulation of goal pursuit in schoolchildren at risk for ADHD. Motivation and Emotion, 37, 134-145.

Gollwitzer, P. M. (1990). Action phases and mind-sets. In E. T. Higgins \& R. M. Sorrentino (Eds.), The handbook of motivation and cognition: Foundations of social behavior (Vol. 2, pp. 53-92). New York, NY: Guilford Press.

Gollwitzer, P. M. (1993). Goal achievement: The role of intentions. European Review of Social Psychology, 4, 141-185.

Gollwitzer, P. M. (1999). Implementation intentions: Strong effects of simple plans. American Psychologist, 54, 493-503.

Gollwitzer, P. M. (2014). Weakness of the will: Is a quick fix possible? Motivation and Emotion, 38, 305-322.
Gollwitzer, P. M., \& Brandstätter, V. (1997). Implementation intentions and effective goal pursuit. Journal of Personality and Social Psychology, 73, 186-199.

Hayes, A. F. (2013). Introduction to mediation, moderation, and conditional process analysis: A regression-based approach. New York, NY: Guilford Press.

Kappes, A., \& Oettingen, G. (2014). The emergence of goal pursuit: Mental contrasting connects future and reality. Journal of Experimental Social Psychology, 54, 25-39.

Kappes, A., Singmann, H., \& Oettingen, G. (2012). Mental contrasting instigates goal pursuit by linking obstacles of reality with instrumental behavior. Journal of Experimental Social Psychology, 48, 811-818.

Kappes, A., Wendt, M., Reinelt, T., \& Oettingen, G. (2013). Mental contrasting changes the meaning of reality. Journal of Experimental Social Psychology, 49, 797-810.

Kirk, D., Oettingen, G., \& Gollwitzer, P. M. (2011). Mental contrasting promotes integrative bargaining. International Journal of Conflict Management, 22, 324-341.

Koski-Janne, A., \& Cunningham, J. A. (2001). Interest in different forms of self-help in a general population sample of drinkers. Addictive Behaviors, 26, 91-99.

Liang, K.-Y., \& Zeger, S. L. (1986). Longitudinal data analysis using generalized linear models. Biometrika, 73, 13-22.

Marquardt, M. K., Oettingen, G., Gollwitzer, P. M., Sheeran, P., \& Liepert, J. (2017). Mental Contrasting with Implementation Intentions (MCII) improves physical activity and weight loss among stroke patients over one year. Rehabilitation Psychology, 62, 580-590.

Miles, J. D., \& Proctor, R. W. (2008). Improving performance through implementation intentions: Are preexisting response biases replaced? Psychonomic Bulletin \& Review, 15, 11051110 .

Miller, W. R., \& Rollnick, S. (1991). Motivational interviewing: Preparing people to change addictive behavior. New York, NY: Guilford Press.

National Institute on Alcohol Abuse and Alcoholism. (2000). 10th special report to the U.S. Congress on alcohol and health: Highlights from current research from the Secretary of Health and Human Services. Washington, DC: U.S. Department of Health and Human Services.

Oettingen, G. (2000). Expectancy effects on behavior depend on self-regulatory thought. Social Cognition, 18, 101-129.

Oettingen, G. (2012). Future thought and behavior change. European Review of Social Psychology, 23, 1-63.

Oettingen, G. (2014). Rethinking positive thinking: Inside the new science of motivation. New York, NY: Penguin Random House.

Oettingen, G., Kappes, H. B., Guttenberg, K. B., \& Gollwitzer, P. M. (2015). Self-regulation of time management: Mental contrasting with implementation intentions. European Journal of Social Psychology, 45, 218-229.

Oettingen, G., \& Gollwitzer, P. M. (2010). Strategies of setting and implementing goals: Mental contrasting and implementation intentions. In J. E. Maddux \& J. P. Tangney (Eds.), Social psychological foundations of clinical psychology (pp. 114-135). New York, NY: Guilford Press.

Oettingen, G., \& Gollwitzer, P. M. (2018). Health behavior change by self-regulation of goal pursuit. In D. de Ridder, M. Adriaanse \& K. Fujita (Eds.), The Routledge international handbook of 
self-control in health and well-being (pp. 418-430). New York, NY: Routledge.

Oettingen, G., Mayer, D., Sevincer, T. A., Stephens, E. J., Pak, H.J., \& Hagenah, M. (2009). Mental contrasting and goal commitment: The mediating role of energization. Personality and Social Psychology Bulletin, 35, 608-622.

Oettingen, G., Pak, H., \& Schnetter, K. (2001). Self-regulation of goal setting: Turning free fantasies about the future into binding goals. Journal of Personality and Social Psychology, 80, 736-753.

Parks-Stamm, E. J., Gollwitzer, P. M., \& Oettingen, G. (2007). Action control by implementation intentions: Effective cue detection and efficient response initiation. Social Cognition, 25, 248-266.

Pedersen, E. R., Grow, J., Duncan, S., Neighbors, C., \& Larimer, M. E. (2012). Concurrent validity of an online version of the timeline followback assessment. Psychology of Addictive Behaviors, 26, 672-677.

Riper, H., Blankers, M., Hadiwijaya, H., Cunningham, J. A., Clarke, S., Wiers, R., . . . Cuijpers, P. (2014). Effectiveness of guided and unguided low-intensity internet interventions for adult alcohol misuse: A meta-analysis. PLoS One, 9, e99912.

Rollnick, S., Heather, N., Gold, R., \& Hall, W. (1992). Development of a short "readiness to change" questionnaire for use in brief, opportunistic interventions among excessive drinkers. British Journal of Addiction, 87, 743-754.

Rooke, S., Thorsteinsson, E., Karpin, A., Copeland, J., \& Allsop, D. (2010). Computer-delivered interventions for alcohol and tobacco use: A meta-analysis. Addiction, 105, 1-10.

Sacks, J. J., Gonzales, K. R., Bouchery, E. E., Tomedi, L. E., \& Brewer, R. D. (2010). 2010 national and state costs of excessive alcohol consumption. American Journal of Preventive Medicine, 49, e73-e79.

Sheeran, P., Webb, T. L., \& Gollwitzer, P. M. (2005). The interplay between goal intentions and implementation intentions. Personality and Social Psychology Bulletin, 31, 87-98.

Sobell, L., \& Sobell, M. (1992). Timeline follow-back: A technique for assessing self-reported alcohol consumption. In J. Allen \& R. Z. Litten (Eds.). Measuring alcohol consumption: Psychosocial and biochemical methods (pp. 41-72). Totowa, NJ: Humana Press.
Stadler, G., Oettingen, G., \& Gollwitzer, P. M. (2009). Physical activity in women. American Journal of Preventive Medicine, 36, 29-34.

Stadler, G., Oettingen, G., \& Gollwitzer, P. M. (2010). Intervention effects of information and self-regulation on eating fruits and vegetables over two years. Health Psychology, 29, 274-283.

Stahre, M., Roeber, J., Kanny, D., Brewer, R. D., \& Zhang, X. (2014). Contribution of excessive alcohol consumption to deaths and years of potential life lost in the United States. Preventing Chronic Disease, 11, E109.

Tabachnick, B. G., \& Fidell, L. S. (2012). Using multivariate statistics. Boston, MA: Pearson Education.

U.S. Preventive Services Task Force. (2013). Screening and behavioral counseling interventions in primary care to reduce alcohol misuse: U.S. Preventive Services Task Force recommendation statement. Annals of Internal Medicine, 159, 210-218.

Walters, S. T., \& Neighbors, C. (2005). Feedback interventions for college alcohol misuse: What, why and for whom? Addictive Behaviors, 30, 1168-1182.

Webb, T. L., \& Sheeran, P. (2006). Does changing behavioral intentions engender behavior change? A meta-analysis of the experimental evidence. Psychological Bulletin, 132, 249-268.

Webb, T. L., \& Sheeran, P. (2007). How do implementation intentions promote goal attainment? A test of component processes. Journal of Experimental Social Psychology, 43, 295-302.

Webb, T. L., \& Sheeran, P. (2008). Mechanisms of implementation intention effects: The role of goal intentions, self-efficacy, and accessibility of plan components. British Journal of Social Psychology, 47, 373-395.

Williams, B. T. R., \& Drummond, C. D. (1994). The Alcohol Problems Questionnaire: Reliability and validity. Drug and Alcohol Dependence, 35, 239-243.

World Health Organization. (2014). Global status report on noncommunicable diseases 2014. Geneva, Switzerland: WHO Press.

Zhou, H., \& Fishbach, A. (2016). The pitfall of experimenting on the web: How unattended selective attrition leads to surprising (yet false) research conclusions. Journal of Personality and Social Psychology, 111, 493-504. 